\title{
Baclofen for narcolepsy with cataplexy: two cases
}

\author{
This article was published in the following Dove Press journal: \\ Nature and Science of Sleep \\ 29 July 2015 \\ Number of times this article has been viewed
}

\author{
Elliott Kyung Lee ${ }^{1,2}$ \\ Alan Bruce Douglass ${ }^{1,2}$ \\ 'Department of Psychiatry, Faculty of \\ Medicine, Institute of Mental Health \\ Research, University of Ottawa, \\ ${ }^{2}$ Royal Ottawa Mental Health Center, \\ Ottawa, ON, Canada
}

\begin{abstract}
Narcolepsy is a disabling sleep disorder characterized by daytime hypersomnolence. Those with cataplexy have spells of muscle weakness precipitated by strong emotions, especially laughter or surprise. Cataplexy treatments include antidepressants or a GABA-B agonist, gamma hydroxybutyrate (GHB). GHB is the most effective treatment for cataplexy, but is expensive and can have significant side effects. A recent report of a murine model of narcolepsy-cataplexy suggests R-baclofen has potential efficacy against cataplexy. We report on two narcolepsy patients with multiple daily cataplexy episodes, one of whom had been effectively treated with GHB, but had to discontinue it for unrelated medical reasons. Both subsequently tried baclofen and experienced almost complete resolution of cataplexy. This report suggests baclofen can be an effective treatment for cataplexy in humans and warrants further study.
\end{abstract}

Keywords: hypersomnolence, gamma hydroxybutyrate, excessive daytime sleepiness

\section{Introduction}

Many patients with narcolepsy suffer from cataplexy - bouts of bilateral muscle weakness triggered by strong emotions such as laughter or surprise. ${ }^{1}$ Existing treatments for cataplexy include serotonergic antidepressants like clomipramine or mixed serotonergic/noradrenergic agents such as venlafaxine. Gamma hydroxybutyrate (GHB), a GABA-B agonist, ${ }^{2}$ is currently the most effective known treatment for cataplexy. While a 2009 study by Huang and Guilleminault ${ }^{3}$ of 13 narcolepsy-cataplexy patients treated with another GABA-B agonist, baclofen, yielded negative results, a recent report in a mouse model has suggested that R-baclofen may have anticataplectic effects. ${ }^{4}$ We report on two patients with narcolepsy-cataplexy who experienced significant anticataplectic benefits from baclofen. Both patients have completed a consent form permitting use of their data for the purposes of this paper. The Institute of Mental Health Research Ethics Board (Royal Ottawa Mental Health Center, University of Ottawa, Ottawa, ON, Canada) reviewed the consent forms and cases, and approved this study (July 24, 2014).

\section{Report of case I}

This was a 28 -year-old female whose symptoms began at age 16 , following a bout of mononucleosis: uncontrollable daytime sleep attacks (eg, class notes began coherently but trailed off to scribbles); sleep paralysis; and hypnagogic hallucinations. Within 1 year, she developed episodes of bilateral upper and lower extremity muscle weakness occurring two to three times per day leading to collapse to the ground; these were triggered by laughter, surprise, anger, or strong emotions. In one instance, she described
Correspondence: Elliott Kyung Lee Royal Ottawa Mental Health Center, Office 3I 25, I I 45 Carling Avenue, Ottawa, ON KIZ 7K4, Canada

Email elliott.lee@theroyal.ca submit your manuscript | www.dovepress.com

Dovepress

http://dx.doi.org// 0.21 $47 /$ NSS.S86649
Nature and Science of Sleep 2015:7 8I-83

(c) (1) (5) 2015 Lee and Douglass. This work is published by Dove Medical Press Limited, and licensed under Creative Commons Attribution - Non Commercial (unported, v3.0) License. The full terms of the License are available at http://creativecommons.org/licenses/by-nc/3.0/. Non-commercial uses of the work are permitted without any further permission from Dove Medical Press Limited, provided the work is properly attributed. Permissions beyond the scope of the License are administered by Dove Medical Press Limited. Information on
how to request permission may be found at: http://www.dovepress.com/permissions.php 
a cataplexy episode where after getting quite upset at the top of some stairs, she collapsed and fell down the stairs, and could see each of the stairs coming at her face, while she was unable to move. While the nocturnal polysomnogram did not show significant sleep-disordered breathing or periodic limb movement activity, a multiple sleep latency test (MSLT) confirmed the diagnosis of narcolepsy. Head imaging studies were non contributory. She tried numerous drugs to treat sleepiness and cataplexy, including venlafaxine, fluoxetine, paroxetine, clomipramine, citalopram, modafinil, and methylphenidate. These gave only partial control of cataplexy and sleepiness. At age 24 she was started on GHB, which resulted in complete resolution of cataplexy within 1-2 months using $4.5 \mathrm{~g} /$ night in divided doses. Daytime sleepiness was controlled with dextroamphetamine. In follow-up over 2 years, she has had excellent control of her narcolepsy-cataplexy with this combination. She was followed-up on average once every 1-3 months in this time interval to monitor her GHB usage. On two occasions, she required dental procedures and pain medications that necessitated temporary discontinuation of GHB which resulted in rebound cataplexy, but then symptoms remitted with GHB resumption. Unfortunately, she developed a gastric motility problem and then found the nausea due to GHB intolerable. Consequently, she began baclofen at bedtime and titrated this to $30 \mathrm{mg}$. Within 4 weeks she experienced complete resolution of cataplexy, without any side effects, except for some mild daytime sleepiness that quickly dissipated by the late morning. At our last visit, approximately 8 months after starting baclofen, she had been cataplexy free, despite experiencing several emotional events including swimming with dolphins, and having her grandfather pass away. She was able to do the eulogy without any evidence of cataplexy, which was a remarkable feat for her.

\section{Report of case 2}

This lady was assessed for narcolepsy with cataplexy at age 38 , after years of excessive daytime sleepiness. She required naps every day at work in her 20 s, and had four episodes where she drove off the highway because of her sleepiness. She recalled being nicknamed "fainter" since age 13, because she would collapse at times of laughter or sudden anger. She had daily visual hypnagogic hallucinations with sleep paralysis. Cataplexy symptoms included bilateral tingling and fasciculation of the facial muscles, weakness of both arms, and knees giving way leading to collapse. The polysomnogram (performed without any medication use) showed minimal sleep-disordered breathing, and a total sleep time of
6 hours and 41 minutes, with a rapid eye movement (REM) latency of 96 minutes. The next day MSLT showed 4/4 naps with sleep-onset REM intrusion and mean sleep latency of 2.5 minutes. Treatment with modafinil, $300 \mathrm{mg}$ every morning (qAM) plus $200 \mathrm{mg}$ at 2 pm largely controlled her sleepiness. Clomipramine $100 \mathrm{mg}$ qAM initially was successful for cataplexy. After 5 years, however, clomipramine lost its effect against cataplexy; venlafaxine $150 \mathrm{mg}$ qAM regained control. After another year, however, cataplexy spells recurred one to three times daily despite venlafaxine use. She then took herself off all medications, which resulted in severe cataplexy, up to ten episodes per day. She could not afford GHB. Then a crisis occurred: she started laughing in the bath tub, had cataplexy, and nearly drowned. The next day, baclofen was started at $20 \mathrm{mg}$ every night (qHS) and cataplexy remitted over the next 6 days. Follow-up has continued for 3 years since, with dosage being increased to $30 \mathrm{mg}$ qHS after the first year due to the return of partial cataplexy; this was fully successful without any side effects.

\section{Discussion}

To our knowledge, this is the first human report documenting the efficacy of baclofen for the treatment of cataplexy, contradicting the previous negative report. ${ }^{3}$ There are several limitations to our two case reports. Unfortunately, neither of our cases of narcolepsy with cataplexy was verified with cerebrospinal fluid hypocretin levels or HLA (human leukocyte antigen) typing. In the first case, the details of the nocturnal polysomnogram and MSLT were unavailable for review, as these were done at an outside facility, and only referenced in the previous doctor's report. Additionally, there is no polysomnography data available for each case after baclofen therapy was initiated.

Despite these limitations, the patients demonstrated clear symptoms of narcolepsy with cataplexy that were validated by objective testing. Each patient also initiated baclofen therapy and experienced significant improvement in symptoms with this medication and this has persisted. Both patients demonstrated severe cataplexy symptoms without treatment, with the first patient responding very well to GHB. Our results are in contrast to the results of Huang and Guilleminault, but there may be several potential explanations for this. It is possible that baclofen was more effective for our patients because of the higher dosage used with our patients compared to the dosage used in Huang and Guilleminault's study. Additionally, our patients had cataplexy for many years and were older before trying baclofen, compared to the patients of Huang and Guilleminault's study who were 
primarily adolescents, possibly accounting for our patients' ability to tolerate higher doses of baclofen. It is possible that baclofen has differential effects on sleep in adults compared to adolescents.

Current data suggest that GHB and baclofen have similar actions at the $\mathrm{GABA}_{\mathrm{B}}$ receptor, but there are pharmacologic differences between these drugs. Perhaps most notable is that baclofen has a higher affinity for the $\mathrm{GABA}_{\mathrm{B}}$ receptor compared to $\mathrm{GHB},{ }^{5}$ and does not have a comparable abuse potential. ${ }^{6}$ Baclofen has typically been used to treat spasticity and can be administered intrathecally. ${ }^{7}$ GHB is a naturally occurring cerebral metabolite, and exogenous administration of sodium oxybate, the sodium salt of GHB, demonstrates anticataplectic effects within days of initiation. ${ }^{3}$ GHB decreases sleep latency and increases slow-wave sleep in humans and animals. ${ }^{8,9}$ Baclofen shares these properties but baclofen has been shown in one study by Hodor et al, in rats, to induce significant increases non-REM sleep and sleep promotion that are distinct from those seen with GHB. ${ }^{10}$ These changes were dose dependent. The effect of baclofen on REM sleep is less clear, with studies showing baclofen administration could increase, ${ }^{10}$ decrease, ${ }^{11}$ or have no effect $^{12}$ on REM sleep. Whether the sleep promoting effects or effects on non-REM and/or REM sleep may play a role in some potential anticataplectic properties of baclofen is uncertain. Our findings suggest that baclofen could be helpful for cataplexy at moderate night-time doses, possibly in older non-adolescent patients and could be a safer and cheaper alternative to GHB. Baclofen use in narcolepsy with cataplexy therefore warrants further investigation.

\section{Disclosure}

The authors report no conflicts of interest in this work.

\section{References}

1. Dauvilliers Y, Arnulf I, Mignot E. Narcolepsy with cataplexy. Lancet. 2007;369(9560):499-511.

2. Lopez R, Dauvilliers Y. Pharmacotherapy options for cataplexy. Expert Opin Pharmacother. 2013;14(7):895-903.

3. Huang YS, Guilleminault C. Narcolepsy: action of two gammaaminobutyric acid type B agonists, baclofen and sodium oxybate. Pediatr Neurol. 2009;41(1):9-16.

4. Black SW, Morairty SR, Chen TM, et al. GABAB agonism promotes sleep and reduces cataplexy in murine narcolepsy. $J$ Neurosci. 2014;34(19):6485-6494.

5. Lingenhoehl K, Brom R, Heid J, et al. Gamma-hydroxybutyrate is a weak agonist at recombinant GABA(B) receptors. Neuropharmacology. 1999;38(11):1667-1673.

6. Carter LP, Koek W, France CP. Behavioral analyses of GHB: receptor mechanisms. Pharmacol Ther. 2009;121(1):100-114.

7. Bensmail D, Quera Salva MA, Roche N, et al. Effect of intrathecal baclofen on sleep and respiratory function in patients with spasticity. Neurology. 2006;67(8):1432-1436.

8. Mamelak M, Black J, Montplaisir J, Ristanovic R. A pilot study on the effects of sodium oxybate on sleep architecture and daytime alertness in narcolepsy. Sleep. 2004;27(7):1327-1334.

9. Vienne J, Lecciso G, Constantinescu I, et al. Differential effects of sodium oxybate and baclofen on EEG, sleep, neurobehavioral performance, and memory. Sleep. 2012;35(8):1071-1083.

10. Hodor A, Palchykova S, Gao B, Bassetti CL. Baclofen and gammahydroxybutyrate differentially altered behavior, EEG activity and sleep in rats. Neuroscience. 2015;284:18-28.

11. Datta S. Activation of pedunculopontine tegmental PKA prevents GABAB receptor activation-mediated rapid eye movement sleep suppression in the freely moving rat. J Neurophysiol. 2007;97(6):3841-3850.

12. Manfridi A, Brambilla D, Mancia M. Sleep is differently modulated by basal forebrain GABA(A) and GABA(B) receptors. Am J Physiol Regul Integr Comp Physiol. 2001;281(1):R170-R175.
Nature and Science of Sleep

\section{Publish your work in this journal}

Nature and Science of Sleep is an international, peer-reviewed, open access journal covering all aspects of sleep science and sleep medicine, including the neurophysiology and functions of sleep, the genetics of sleep, sleep and society, biological rhythms, dreaming, sleep disorders and therapy, and strategies to optimize healthy sleep. The journal welcomes

\section{Dovepress}

original research, clinical \& epidemiological studies, reviews \& evaluations, case reports and extended reports. The manuscript management system is completely online and includes a very quick and fair peerreview system, which is all easy to use. Visit http://www.dovepress.com/ testimonials.php to read real quotes from published authors. 